\title{
Future incidence and mortality of colorectal carcinoma in the United States: an updated overview of risk factors and preventative measures
}

\author{
Hassam Ali $^{*}$ (1) \\ Department of Internal Medicine, East Carolina University/Vidant Medical Center, Greenville, NC 27834, USA
}

*Correspondence: Hassam Ali, Department of Internal Medicine, East Carolina University/Vidant Medical Center, Greenville, NC 27834, USA. alih20@ecu.edu

Academic Editor: Enrico Mini, University of Florence, Italy

Received: May 27, 2021 Accepted: October 8, 2021 Published: December 31, 2021

Cite this article: Ali H. Future incidence and mortality of colorectal carcinoma in the United States: an updated overview of risk factors and preventative measures. Explor Med. 2021;2:455-67. https://doi.org/10.37349/emed.2021.00063

\begin{abstract}
According to the Global Cancer Observatory (GLOBOCAN) 2020, colorectal carcinoma (CRC) was the second leading cause of cancer death globally. Current literature utilizes reported databases such as Surveillance, Epidemiology, and End Results (SEER) to better understand the epidemiology of CRC. The global cancer observatory's "Cancer Tomorrow" data visualization tools were used to predict the future incidence and mortality of colorectal cancers until 2030 as a guided tool to look over ways to reduce incidence by controlling risk factors of CRC. The total number of CRC is expected to rise by 2030, with a percent change of $17.3 \%$. The expected percent change in colon cancer is more than rectal cancer (19.8\% vs. $11.6 \%)$. The estimated number of deaths secondary to CRC is expected to increase in 2030, an estimated percent change of $22.2 \%$. The incidence and mortality rate was higher in men $v s$. women; however, the gap seems to be closing on trend analysis. Major risk factors for CRC include familial syndromes, family history, race, gender, obesity, diet, alcohol, and smoking. Risk can be reduced by exercise and dietary changes, fiber intake, vitamin D, calcium, and minerals. Individualized screening based on age, gender, and additional risk factors could be an option that needs further comparative data to propose a definitive benefit over established screening guidelines.
\end{abstract}

\section{Keywords}

Colorectal carcinoma incidence, colorectal carcinoma mortality, colorectal carcinoma risk, CRC, GLOBOCAN

\section{Introduction}

Colorectal cancer (CRC) was the second leading cause of cancer death in the United States and the fourth most common cancer by its incidence in 2020, which continues to rise steadily [1]. CRC emerges from the glandular epithelial cells of the colon. Specific genetic or epigenetic mutations confer change on the normal cellular structure resulting in their ability to become dysplastic. These cells can then give rise to benign adenoma, which may then evolve into carcinoma [2,3]. Based on previously reported national cancer statistics, the incidence and mortality of colorectal carcinomas have been decreasing [4]. However, data from

(C) The Author(s) 2021. This is an Open Access article licensed under a Creative Commons Attribution 4.0 International License (https://creativecommons.org/licenses/by/4.0/), which permits unrestricted use, sharing, adaptation, distribution and reproduction in any medium or format, for any purpose, even commercially, as long as you give appropriate credit to the original author(s) and the source, provide a link to the Creative Commons license, and indicate if changes were made. 
United States Surveillance, Epidemiology, and End Results (SEER) database suggest that CRC incidence is increasing in the under age 50 group and decreasing in older groups despite age being a significant risk factor for CRC [5, 6]. Most cases diagnosed at younger ages are reportedly symptomatic and at later stages, suggesting that the increased incidence is accurate and not representative of lead-time bias attributable to earlier detection [6]. Major risk factors for CRC include cancer history in a first-degree relative, obesity, hyperlipidemia, age, and alcohol consumption [7]. In the US, the lifetime incidence of CRC for average-risk patients is 4\% [8]. CRC incidence is approximately four times higher in males than females, and African Americans have a five times higher chance of CRC than whites [9]. While most literature utilizes currently reported cases and databases such as SEER to understand the epidemiology of CRC, few studies talk about the future incidence and measures that can be employed to reduce further escalation. A more robust understanding of the CRC incidence in the future, its modifiable and non-modifiable risk factors, and the preventative measures will empower researchers and physicians to prevent this fatal neoplasm.

\section{Future incidence and mortality}

Global Cancer Observatory (GLOBOCAN) Cancer Tomorrow provides data visualization tools to predict the future incidence and mortality of various cancers from the current estimates. The data is based on a predictive model that estimates the incidence, mortality, and prevalence [1,10]. Cancer Tomorrow reports the global cancer statistics to inform cancer control and research. It enables a derivation of the future cancer burden based on the current GLOBOCAN estimates. Cancer Tomorrow computes expected incidence and mortality data by multiplying the age-specific incidence/mortality rates estimated for 2020 by the corresponding expected population for future years. These expected populations are different from what is used to compute the estimated rates. However, cancer predictions should be interpreted with due caution [11].

\section{Incidence rates and trends of CRC by 2030}

According to GLOBOCAN 2020 data, 146,589 cases of CRC were reported in the US, (males = 78,837, females $=67,752$ ). The number of colon cancer cases was 101,809 (males $=51,715$, females $=50,094)$. The cases of rectal cancers in the US in 2020 were 44,780 (males $=27,122$, females $=17,658$ ). The total number of CRC is expected to rise to 170,968 by 2030 , with a percent change of $17.3 \%$. The expected percent change in colon cancers is more than rectal cancers $(19.8 \%$ vs. $11.6 \%)$. The number of cases is expected to remain more common in males than females, with higher percent changes in 2030, as reported in Table 1.

Table 1. Incidence/case counts and percent changes in 2020 and 2030 of colorectal, colon and rectal carcinomas

\begin{tabular}{llll}
\hline Cancer subtype & Total number of cases in 2020 & Total number of cases in 2030 & Percent change \\
\hline Colorectal cases (total) & 146,589 & 170,968 & $17.3 \%$ \\
Colorectal cases in males & 78,837 & 91,804 & $17.6 \%$ \\
Colorectal cases in females & 67,752 & 79,164 & $16.8 \%$ \\
Colon cancer cases (total) & 101,809 & 121,923 & $19.8 \%$ \\
Colon cancer cases in males & 51,715 & 62,398 & $20.7 \%$ \\
Colon cancer cases in females & 50,094 & 59,525 & $18.8 \%$ \\
Rectal cancer cases (total) & 44,780 & 49,968 & $11.6 \%$ \\
Rectal cancer cases in males & 27,122 & 30,329 & $11.8 \%$ \\
Rectal cancer cases in females & 17,658 & 19,639 & $11.2 \%$ \\
\hline
\end{tabular}

The predicted incidence trends in CRC are demonstrated in Figure 1. The gap between males and females is lower in colon cancer (Figure 2) as compared to rectal cancer (Figure 3). 


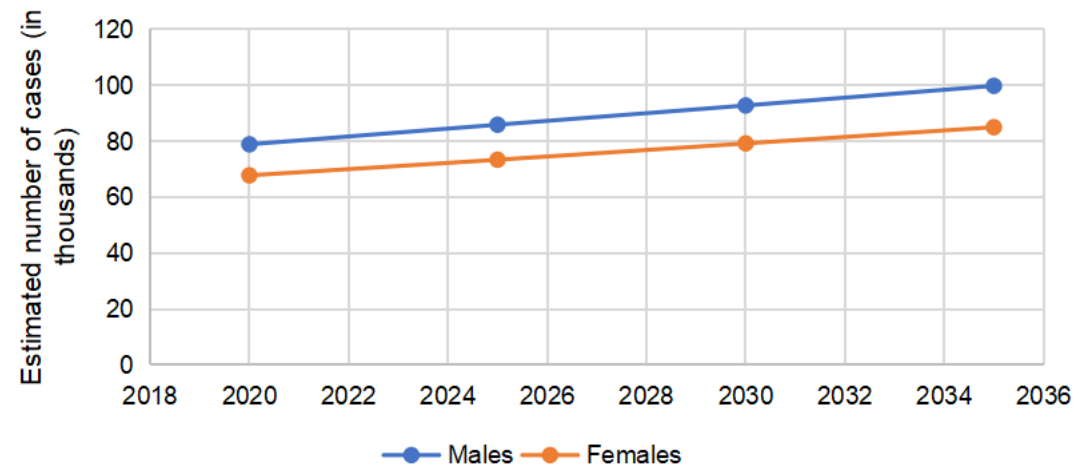

Figure 1. Predicted incidence trends of colorectal carcinomas in males and females

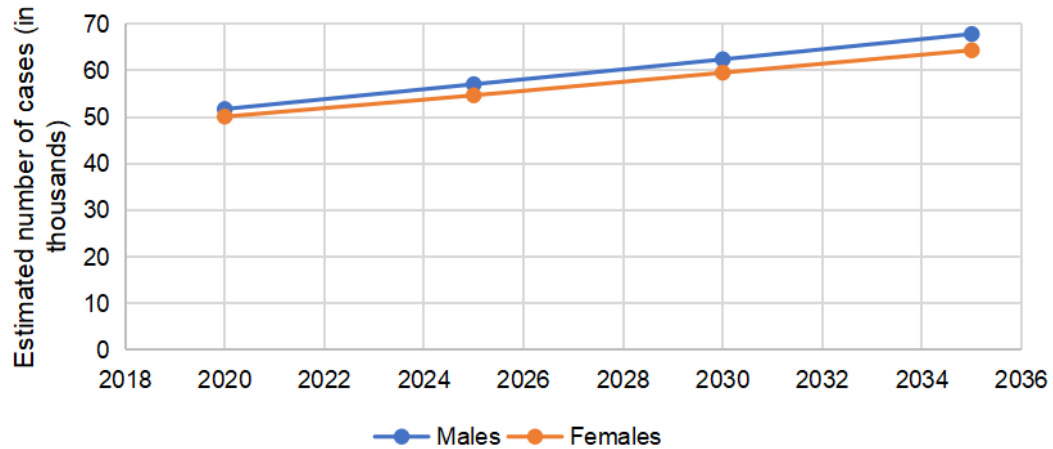

Figure 2. Predicted incidence trends of colon carcinomas in males and females

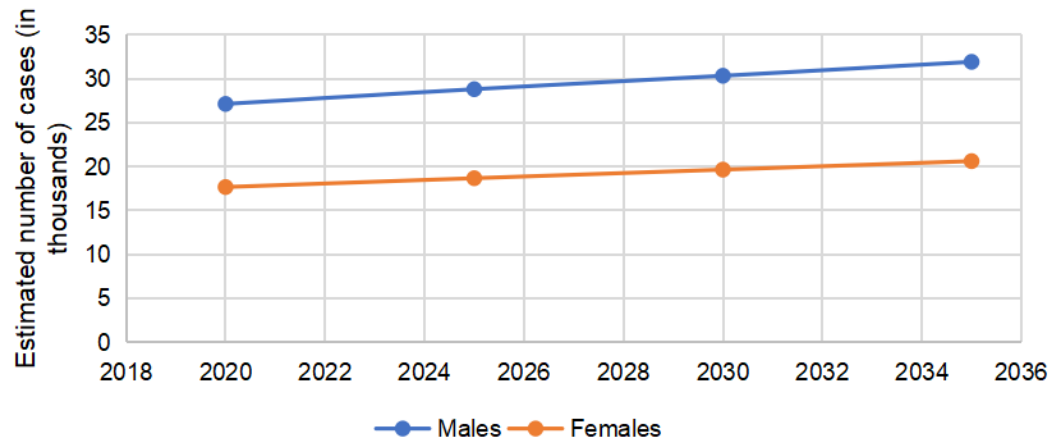

Figure 3. Predicted incidence trends of rectal carcinomas in males and females

\section{Mortality rates and trends of CRC by 2030}

An estimated 53,069 (males $=28,405$, females $=24,664$ ) people passed away secondary to colorectal carcinoma in the US in 2020. The number of deaths due to colon cancer alone was 37,930 (males $=19,020$, females $=18,910$ ). The number of cases in for rectal cancer was 15,139 (males $=9,385$, females $=5,754$ ). The estimated number of deaths secondary to CRC is expected to go up to 64,553 (males $=34,368$, females $=30,185$ ) in 2030 , an estimated percent change of $22.2 \%$. The percent changes for males and females are similar for predicted mortality rates of CRC in 2030 (Table 2).

Table 2. Number of deaths (mortality) in 2020 and 2030 from colorectal, colon and rectal carcinomas

\begin{tabular}{llll}
\hline Cancer subtype & Total number of deaths in 2020 & Total number of deaths in 2030 & Percent change \\
\hline Colorectal cases (total) & 53,069 & 64,889 & $22.3 \%$ \\
Colorectal cases in males & 28,405 & 34,317 & $22.2 \%$ \\
Colorectal cases in females & 24,664 & 30,185 & $22.4 \%$ \\
Colon cancer cases (total) & 37,930 & 46,833 & $23.5 \%$ \\
Colon cancer cases in males & 19,020 & 23,519 & $23.7 \%$ \\
Colon cancer cases in females & 18,910 & 23,314 & $23.3 \%$ \\
Rectal cancer cases (total) & 15,139 & 18,066 & $19.3 \%$ \\
Rectal cancer cases in males & 9,385 & 11,194 & $19.3 \%$ \\
Rectal cancer cases in females & 5,754 & 6,871 & $19.4 \%$ \\
\hline
\end{tabular}


The predicted mortality trends in CRC are separately demonstrated in Figure 4. Gap in mortality trends in rectal cancer appeared to be wider (Figure 5); however, in colon cancer the trends were almost similar (Figure 6).

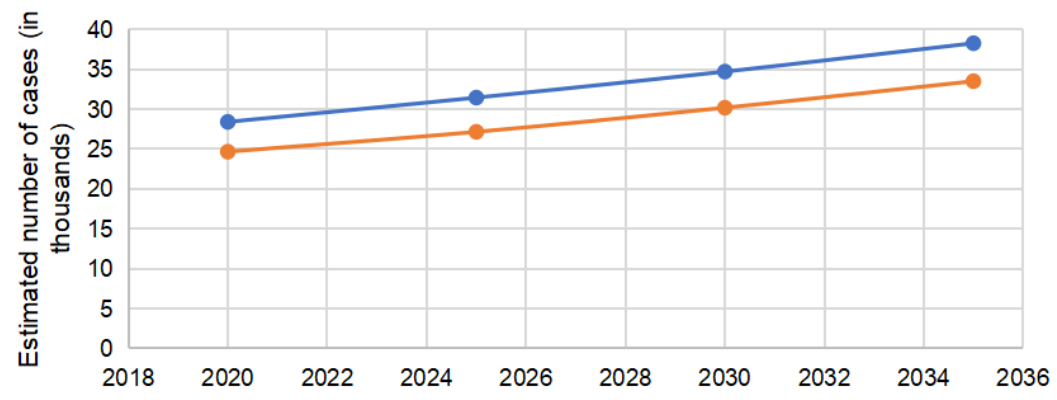

Figure 4. Predicted mortality trends of colorectal carcinoma in males and females

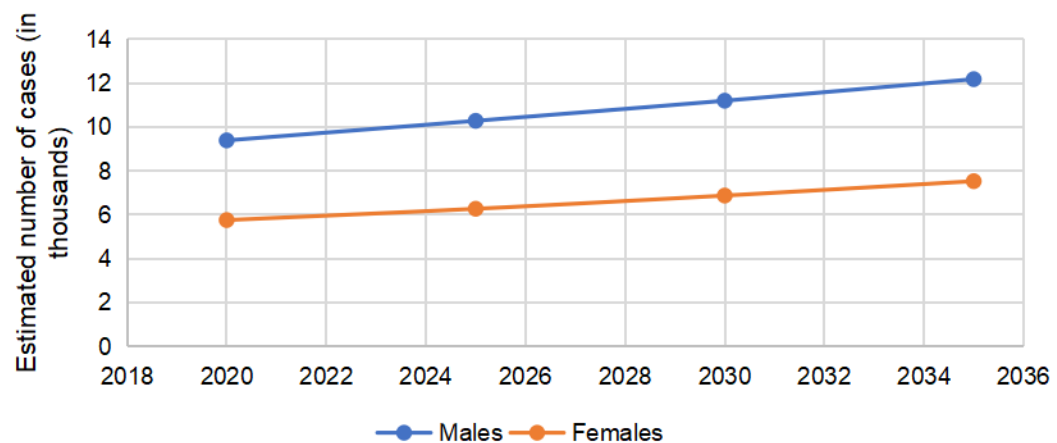

Figure 5. Predicted mortality trends of rectal carcinoma in males and females

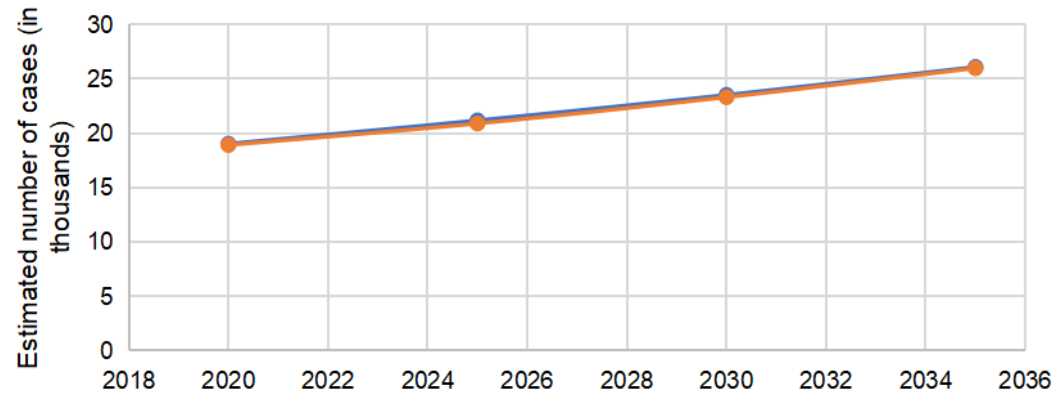

Figure 6. Predicted mortality trends of colon carcinoma in males and females

\section{Risk factors}

Colorectal carcinomas are multifactorial, with both environmental and genetic factors influencing their development [12]. The majority of cases are not familial rather sporadic in nature. The risk factors behind the development of CRCs can be broadly classified into modifiable and non-modifiable risk factors. Revisiting these risk factors can help better understand the associated future risk of CRC and reduce its incidence and mortality.

\section{Non-modifiable risk factors}

Familial CRC syndromes

Two of the known syndromes which are associated with a high risk of developing colon cancer are familial adenomatous polyposis (FAP) and Lynch syndrome/hereditary nonpolyposis colorectal cancer (HNPCC). Lynch syndrome more commonly causes colon cancer than FAP [13]. FAP results from a germline mutation in the adenomatous polyposis coli $(A P C)$ gene located on chromosome 5. In attenuated FAP, a less severe form, a similar gene is involved, but the site of the APC gene mutation is different [14]. In typical FAP, multiple colonic adenomas start appearing in early childhood, and colonic cancer occurs in $90 \%$ of untreated 
individuals by age 45 [15]. Lynch syndrome or HNPCC is an autosomal-dominant syndrome that accounts for approximately $3 \%$ of all colonic carcinomas [16]. Family history of CRC, endometrial, and other cancers could increase suspicion of Lynch syndrome. Patients with Lynch syndrome have a germline mutation in mismatch repair (MMR) gene. The second allele gets inactivated by mutation, loss of heterozygosity, or epigenetic silencing resulting in impaired DNA MMR and is microsatellite instability [17]. Lynch syndrome often has extracolonic manifestations, including endometrial carcinoma, increased risk of neoplasm formation of ovaries, gastrointestinal tract, hepatobiliary system, and genitourinary system [18].

\section{Family history}

Patients with a positive family history of colorectal carcinomas or personal history of adenomatous polyps are at a greater risk for colon cancer than the general population. One first-degree relative with CRC doubles the risk of colon cancer [19]. One first and one or more first or second-degree relatives or a first-degree relative who is diagnosed below 50 years of age also increase the risk of colon cancer than the general population (Amsterdam criteria II) [20]. Personal history of $>1 \mathrm{~cm}$ adenomatous polyps or villous or tubulovillous polyps or high-grade dysplasia increases the risk of CRC as well [21]. However, smaller tubulous adenomas and low-grade dysplastic lesions do not considerably increase CRC risk [21].

\section{Inflammatory bowel diseases}

Inflammatory bowel disease (IBD) constitutes ulcerative colitis and Crohn's disease. Association between ulcerative colitis and colon cancer is well documented; risk factors include young age at diagnosis, chronicity, greater anatomical involvement, the degree of inflammation, family history of CRC, and presence of primary sclerosing cholangitis $[22,23]$. Ulcerative colitis results in inflammation and ulcers of the colon. While the primary cause remains unknown, it is believed to be an autoimmune disorder with a possible hereditary component. Ulcerative colitis may double the risk of CRC [24]. Crohn's disease is characterized by transmural inflammation and involves any part of the luminal gastrointestinal tract. Although evidence is still incomplete regarding the increased incidence of colorectal carcinoma in Crohn's disease, patients are at increased risk of colon cancer-related mortality and diagnosis [25].

\section{Radiation therapy}

Abdominopelvic radiation therapy (childhood or adulthood) has been associated with an increased incidence of colorectal carcinomas. Radiation and alkylator exposure are both considered the culprits for secondary CRC [26]. Although no consensus currently exists to initial CRC screening in patients with a history of abdominopelvic radiation, colonoscopy every five years after radiation therapy or at age 30 years, whichever occurs last, multitarget stool DNA test every three years, and screening every ten years from age 40 to 60 years has been suggested [27].

\section{Cystic fibrosis}

Patients with cystic fibrosis (CF) have an increased risk of CRC; a recent meta-analysis showed that patients with lung transplantation secondary to CF had a two to five times increased chance of developing colorectal carcinoma than the general population [28]. According to the cystic fibrosis foundation taskforce, CRC screening initiates at age 40, with a five-year re-screening interval [29]. Additionally, organ transplant recipients secondary to $\mathrm{CF}$ should have an initial screening at age 30 years (within two years of the transplantation) due to additional risk for colon cancer linked to immunosuppressive therapy [29].

\section{Race}

CRC incidence is higher in African Americans vs. other ethnicities in the US. The mortality is approximately 20\% higher in African Americans than Whites [9]. CRC incidence is also higher in the younger age groups of less than 50 in African Americans. Screening is now recommended to start at 45 in African Americans, and colonoscopy is the preferred screening test. Screening for other ethnicities is recommended at age 50; however, recent guidelines suggest starting screening in average-risk individuals between ages 45 and 49 years [30]. 


\section{Gender}

Although the gender difference has been shrinking for CRC incidence in the US, its associated mortality is higher in men [31]. Both colonic adenomas and CRC have more proximal distribution in women [32]. Individualized screening has been suggested previously based on risk factors including gender [33].

\section{Renal transplantation and immunosuppression}

Renal transplantation (with long-term immunosuppression) has been linked with increased CRC risk [34]. Additionally, Epstein-Barr virus (EBV) positive serology is more common in renal transplant patients with colon cancer, and it may be contributing to the etiology [34].

\section{Acromegaly}

Increased incidence of adenomatous colonic polyps and colon cancers has been proposed in patients with acromegaly. However, the pathogenies are poorly understood [35]. There could be component of insulin like growth factor's effect on colon mucosal cells.

\section{Modifiable risk factors}

Obesity

Weight gain and obesity have been positively associated with increased CRC risk [36]. It has also been reported that weight loss reduces the risk of CRC. A study showed that following bariatric surgery, CRC risk in patients with obesity is the same as the general population compared to patients who did not undergo any surgery for weight loss, having approximately greater than $40 \%$ risk of developing CRC than the general population [37].

\section{Insulin resistance and diabetes mellitus}

Diabetes mellitus is associated with an increased risk of CRC [38]. A meta-analysis of 14 studies reported that the risk of colon cancer among people with diabetes was approximately $38 \%$ and $20 \%$ higher for colon and rectal cancer, respectively, as compared to the general population [39]. Hyperinsulinemia could explain this increased risk as insulin is a critical growth factor for colonic mucosal cells and stimulates colonic tumor cells. Insulin-like growth factor 1 (IGF-1) and IGF binding protein-3 (IGFBP-3) have been linked to influencing the risk of CRC positively [40]. Therefore, higher circulating IGF-1 and IGFBP-3 are related to the prospective risk of CRC [40].

Diet

Consumption of red or processed meats on a long-term basis has been associated with an increased risk of CRC, especially left-sided malignancies [41]. It can be argued that higher temperatures linked to the production of polyaromatic hydrocarbons and other carcinogens produced from proteins in the charring process while cooking can be a resulting factor for this increased risk. As a comparison, lean red meat has been associated with reduced risk and reduces the transition of developing adenomas hence halting the process of developing malignancies [42].

\section{Smoking}

Both incidence and mortality from CRC increase secondary to smoking [43]. Additionally, regular smokers with Lynch syndrome may be at increased risk of CRC as compared to former smokers [44].

\section{Alcohol}

Alcohol consumption is another risk factor for multiple malignancies, including CRC [45]. A meta-analysis of 27 cohorts and 34 case-control studies reported a positive relationship with multiple drinks to the risk of developing CRC and provided strong evidence for an association between alcohol drinking of $>1$ drink/day and CRC risk [46]. 


\section{Androgen deprivation therapy}

Androgen deprivation therapy (ADT) in patients with prostate cancer is associated with a higher risk of CRC [47]. Long-term ADT may be a culprit, and the mechanism is currently poorly understood; however, insulin resistance secondary to ADT could be a possible contributor $[47,48]$.

\section{Cholecystectomy}

Limited evidence shows some association between increased incidence of proximal colon cancer and cholecystectomy. The mechanism is related to alterations in bile acid composition in the colon post-cholecystectomy $[49,50]$. However, the evidence is weak, and further data is required to make an absolute conclusion.

\section{Preventative factors}

Changing trends in the incidence of colon and rectal carcinomas suggest a behavioral component. Recently updated guidelines and advances in tools to reduce the incidence and mortality provide physicians with multiple options. Several screening tools are available, including colonoscopy, flexible sigmoidoscopy, computed tomographic colonography (CTG), guaiac-based fecal occult blood test (gFOBT), fecal immunochemical test (FIT), and the multitarget stool DNA, (MT-sDNA, Cologuard $®$ ). The sensitivities and specificities of these tools are variable [51].

Substantial data suggests that regular physical activity is associated with CRC protection, especially a reduced risk of proximal colon and distal colon cancers [52]. In addition to exercise, diet also plays a role, and a diet high in fruits and vegetables has shown a protective effect against CRC [53]. Vegetarian dietary patterns have been associated with a reduced CRC risk compared to nonvegetarians [54]. Intake of fiber can also play a role in reducing CRC and colonic adenomas. One study showed that doubling of total fiber intake in populations with below-average intake may reduce CRC risk up to $40 \%$ [55].

Folate supplementation has also shown some effect on colon cancer; data has demonstrated that folate inhibits cancer pathogenesis in the colon [56]. The mechanism is poorly understood, but folate plays a role in S-adenosylmethionine formation, a methyl donor, and purine and thymidine synthesis. We know that colon cancer is secondary to alterations in DNA methylation, disruption of DNA, and interrupted DNA repair, all of these processes tend to increase with folate depletion [56].

However, this should be taken with a grain of salt. One trial showed increased risks of non-CRC adenomas secondary to folate supplementation, and folic acid at one mg per day did not reduce colorectal adenoma risk. Further research is needed to investigate the effect of folic acid on the risk of colorectal neoplasia [57].

In one meta-analysis of prospective studies, data suggested a modest correlation between higher pyridoxine (vitamin B6) intake and reduced CRC risk [58]. However, evidence is still lacking in this regard. Calcium and vitamin D have also shown some protective effects in colorectal carcinoma development. Daily calcium intake by up to $1,200 \mathrm{mg}$ has been shown to reduce colonic epithelial cell proliferative activity and enables normal cellular differentiation [59]. Calcium supplementation is also linked to reducing the risk of recurrent colorectal adenoma [60]. Vitamin D plays a role in colorectal adenomas etiology, possibly through the vitamin D receptor (VDR). Patients with VDR gene BsmI polymorphism B allele (BB BsmI VDR genotype) may be at decreased risk of colorectal adenoma even if calcium and vitamin D intake is low [61]. However, some studies postulate that calcium and vitamin D supplementation act primarily to reduce colorectal adenoma recurrence risk and the VDR genotype plays no significant role [62]. Vitamin D affects the innate immune response, which can influence the propensity to develop inflammatory bowel diseases, a known predisposing factor for CRC. Vitamin D's role should be better understood as it can provide a role in chemopreventative and cancer therapeutics [63]. One population-based study also implies that a high magnesium intake can reduce the incidence of colorectal cancer in women [64].

Aspirin and nonsteroidal anti-inflammatory drugs (NSAIDs) have a protective role against colonic adenoma and cancer development. The mechanism could be increased apoptosis and impaired tumor cell growth by interference with cyclooxygenase-2 (COX-2) [65]. Long-term daily aspirin therapy at doses of 
$75 \mathrm{mg}$ or greater has been shown to reduce the long-term incidence and mortality due to colorectal cancer, especially in the proximal colon [65]. One randomized control trial also showed a reduced risk of CRC with combination therapy of difluoromethylornithine (DFMO) and sulindac (nonsteroidal anti-inflammatory drug) [66]. Statin therapy has been associated with a reduced risk of colorectal carcinoma. One study shows a $47 \%$ relative reduction in colorectal cancer risk after risk factors adjustment [67]. However, further data is required. Long-term angiotensin converting enzyme inhibitors (ACE inhibitors) therapy has been postulated to reduce CRC development by decreasing advanced adenoma development [68]. In contrast, a case-control study assessing ACE inhibitor exposure and CRC risk did not demonstrate any significant association [69]. It also reported no reduction of CRC risk by use of statins or other lipid-lowering and antihypertensive medications [69]. Individualized CRC screening based on gender and race may also provide benefit in CRC prevention. Race-based guidelines currently only exist for African Americans. However, no individualized guidelines exist based on gender. Early colonoscopy may be recommended on an individual basis based on risk factor [33, 70].

GLOBOCAN is limited as it does not report right and left colon cancer separately. We believe the future projection would have given a more comprehensive idea about rising incidence from an epidemiological point of view. Right-sided colon cancers incidence has been increasing in recent years [71, 72]. The right-sided colon is associated with aggressive behavior, but they do not show a more unsatisfactory outcome [73]. FIT's role in screening right-sided colorectal cancer should be explored further as studies show higher mortality and interval cancer rate after a negative FIT result [74]. The cancer localized to the right colon was $41.1 \%$ instead of the left colon and rectum in one study [74]. Therefore, author does suggest that patients should be made aware of the risk of developing cancer after a negative FIT study. Colonoscopy would be a better alternative.

The increased prevalence of colon cancer could also be related to a recently predicted rise in modifiable risk factors [75]. It has been reported that by $2030,50 \%$ of adults will have obesity with greater than $50 \%$ prevalence in 29 states in the US. Additionally, $25 \%$ of adults are projected to have severe obesity by 2030. Diabetes and smoking are also more prevalent in obese people [76]. Patients who undergo surgical management for colorectal cancers have poor morbidity if they have underlying diabetes [77]. One study reported no changes in mortality or morbidity after right or left colectomy; however, the rate of postoperative intra-abdominal fluid collections requiring intervention and the anastomotic leak was higher in obese patients [78].

\section{Conclusion}

Colorectal carcinomas have a destructive potential with rising incidence globally and in the US. GLOBOCAN predicts a growing incidence of both colon and rectal carcinomas in males and females in the next ten years. The exacerbated incidence could be linked to poor diet, sedentary lifestyle, obesity, red meat, alcohol, and smoking. Dietary changes, exercise, aspirin, vitamin, and multi-mineral intake can reduce CRC incidence among the US's general population. Further long-term and comparative data, including comparing current screening guidelines to individualize screening based on age, gender, and risk factors, could hold some promise to flatten the rising curve.

\section{Abbreviations}

ADT: androgen deprivation therapy

CF: cystic fibrosis

CRC: colorectal carcinoma

FAP: familial adenomatous polyposis

FIT: fecal immunochemical test

GLOBOCAN: Global Cancer Observatory

IGF-1: insulin like growth factor 1

VDR: vitamin D receptor 


\section{Declarations}

Author contributions

The author contributed solely to the work.

\section{Conflicts of interest}

The author declares that he has no conflicts of interest.

\section{Ethical approval}

Not applicable.

\section{Consent to participate}

Not applicable.

\section{Consent to publication}

Not applicable.

\section{Availability of data and materials}

The datasets analysed for this study can be found in the Global Cancer Observatory (https://gco.iarc.fr/).

\section{Funding}

Not applicable.

\section{Copyright}

(C) The Author(s) 2021.

\section{References}

1. Cancer Stat Facts: Common Cancer Sites [Internet]. Bethesda: National Cancer Institute; [cited 2021 Mar 10]. Available from: https://seer.cancer.gov/statfacts/html/common.html

2. Ewing I, Hurley JJ, Josephides E, Millar A. The molecular genetics of colorectal cancer. Frontline Gastroenterol. 2014;5:26-30.

3. Vogelstein B, Fearon ER, Hamilton SR, Kern SE, Preisinger AC, Leppert M, et al. Genetic alterations during colorectal-tumor development. N Engl J Med. 1988;319:525-32.

4. Henley SJ, Ward EM, Scott S, Ma J, Anderson RN, Firth AU, et al. Annual report to the nation on the status of cancer, part I: national cancer statistics. Cancer. 2020;126:2225-49.

5. Abualkhair WH, Zhou M, Ahnen D, Yu Q, Wu XC, Karlitz JJ. Trends in incidence of early-onset colorectal cancer in the United States among those approaching screening age. JAMA Netw Open. 2020;3:e1920407.

6. Meester RGS, Mannalithara A, Lansdorp-Vogelaar I, Ladabaum U. Trends in incidence and stage at diagnosis of colorectal cancer in adults aged 40 through 49 years, 1975-2015. JAMA. 2019;321:1933-4.

7. O'Sullivan DE, Sutherland RL, Town S, Chow K, Fan J, Forbes N, et al. Risk factors for early-onset colorectal cancer: a systematic review and meta-analysis. Clin Gastroenterol Hepatol. 2021;[Epub ahead of print].

8. Siegel RL, Miller KD, Fuchs HE, Jemal A. Cancer statistics, 2021. CA Cancer J Clin. 2021;71:7-33.

9. Jemal A, Siegel R, Xu J, Ward E. Cancer statistics, 2010. CA Cancer J Clin. 2010;60:277-300.

10. Cancer Tomorrow [Internet]. Lyon: International Agency for Research on Cancer. c1965-2020 [cited 2021 Apr 1]. Available from: https://gco.iarc.fr/tomorrow

11. Ferlay J, Colombet M, Soerjomataram I, Mathers C, Parkin DM, Piñeros M, et al. Estimating the global cancer incidence and mortality in 2018: GLOBOCAN sources and methods. Int J Cancer. 2019; 144:1941-53. 
12. Chan AT, Giovannucci EL. Primary prevention of colorectal cancer. Gastroenterology. 2010;138: 2029-43.e10.

13. Lynch HT, Smyrk TC, Watson P, Lanspa SJ, Lynch JF, Lynch PM, et al. Genetics, natural history, tumor spectrum, and pathology of hereditary nonpolyposis colorectal cancer: an updated review. Gastroenterology. 1993;104:1535-49.

14. Vasen HF, Tomlinson I, Castells A. Clinical management of hereditary colorectal cancer syndromes. Nat Rev Gastroenterol Hepatol. 2015;12:88-97.

15. Half E, Bercovich D, Rozen P. Familial adenomatous polyposis. Orphanet J Rare Dis. 2009;4:22.

16. Mishra N, Hall J. Identification of patients at risk for hereditary colorectal cancer. Clin Colon Rectal Surg. 2012;25:67-82.

17. Tiwari AK, Roy HK, Lynch HT. Lynch syndrome in the 21st century: clinical perspectives. QJM. 2016;109:151-8.

18. Koornstra JJ, Mourits MJ, Sijmons RH, Leliveld AM, Hollema H, Kleibeuker JH. Management of extracolonic tumors in patients with Lynch syndrome. Lancet Oncol. 2009;10:400-8.

19. Tuohy TM, Rowe KG, Mineau GP, Pimentel R, Burt RW, Samadder NJ. Risk of colorectal cancer and adenomas in the families of patients with adenomas: a population-based study in Utah. Cancer. 2014;120:35-42.

20. Taylor DP, Stoddard GJ, Burt RW, Williams MS, Mitchell JA, Haug PJ, et al. How well does family history predict who will get colorectal cancer? Implications for cancer screening and counseling. Genet Med. 2011;13:385-91.

21. Atkin WS, Morson BC, Cuzick J. Long-term risk of colorectal cancer after excision of rectosigmoid adenomas. N Engl J Med. 1992;326:658-62.

22. Yashiro M. Ulcerative colitis-associated colorectal cancer. World J Gastroenterol. 2014;20:16389-97.

23. Olén O, Erichsen R, Sachs MC, Pedersen L, Halfvarson J, Askling J, et al. Colorectal cancer in ulcerative colitis: a Scandinavian population-based cohort study. Lancet. 2020;395:123-31.

24. Jess T, Rungoe C, Peyrin-Biroulet L. Risk of colorectal cancer in patients with ulcerative colitis: a meta-analysis of population-based cohort studies. Clin Gastroenterol Hepatol. 2012;10:639-45.

25. Olén O, Erichsen R, Sachs MC, Pedersen L, Halfvarson J, Askling J, et al. Colorectal cancer in Crohn's disease: a Scandinavian population-based cohort study. Lancet Gastroenterol Hepatol. 2020;5:475-84.

26. Nottage K, McFarlane J, Krasin MJ, Li C, Srivastava D, Robison LL, et al. Secondary colorectal carcinoma after childhood cancer. J Clin Oncol. 2012;30:2552-8.

27. Gini A, Meester RGS, Keshavarz H, Oeffinger KC, Ahmed S, Hodgson DC, et al. Cost-effectiveness of colonoscopy-based colorectal cancer screening in childhood cancer survivors. J Natl Cancer Inst. 2019;111:1161-9.

28. Yamada A, Komaki Y, Komaki F, Micic D, Zullow S, Sakuraba A. Risk of gastrointestinal cancers in patients with cystic fibrosis: a systematic review and meta-analysis. Lancet Oncol. 2018;19:758-67.

29. Hadjiliadis D, Khoruts A, Zauber AG, Hempstead SE, Maisonneuve P, Lowenfels AB; Cystic Fibrosis Colorectal Cancer Screening Task Force. Cystic fibrosis colorectal cancer screening consensus recommendations. Gastroenterology. 2018;154:736-45.e14.

30. Shaukat A, Kahi CJ, Burke CA, Rabeneck L, Sauer BG, Rex DK. ACG clinical guidelines: colorectal cancer screening 2021. Am J Gastroenterol. 2021;116:458-79.

31. Brenner H, Hoffmeister M, Arndt V, Haug U. Gender differences in colorectal cancer: implications for age at initiation of screening. Br J Cancer. 2007;96:828-31.

32. Schoenfeld P, Cash B, Flood A, Dobhan R, Eastone J, Coyle W, et al. Colonoscopic screening of average-risk women for colorectal neoplasia. N Engl J Med. 2005;352:2061-8. 
33. Lansdorp-Vogelaar I, van Ballegooijen M, Zauber AG, Boer R, Wilschut J, Winawer SJ, et al. Individualizing colonoscopy screening by sex and race. Gastrointest Endosc. 2009;70:96-108.e24.

34. Park JM, Choi MG, Kim SW, Chung IS, Yang CW, Kim YS, et al. Increased incidence of colorectal malignancies in renal transplant recipients: a case control study. Am J Transplant. 2010;10:2043-50.

35. Delhougne B, Deneux C, Abs R, Chanson P, Fierens H, Laurent-Puig P, et al. The prevalence of colonic polyps in acromegaly: a colonoscopic and pathological study in 103 patients. J Clin Endocrinol Metab. 1995;80:3223-6.

36. Karahalios A, English DR, Simpson JA. Weight change and risk of colorectal cancer: a systematic review and meta-analysis. Am J Epidemiol. 2015;181:832-45.

37. Bailly L, Fabre R, Pradier C, Iannelli A. Colorectal cancer risk following bariatric surgery in a nationwide study of French individuals with obesity. JAMA Surg. 2020;155:395-402.

38. Yang YX, Hennessy S, Lewis JD. Type 2 diabetes mellitus and the risk of colorectal cancer. Clin Gastroenterol Hepatol. 2005;3:587-94.

39. Yuhara H, Steinmaus C, Cohen SE, Corley DA, Tei Y, Buffler PA. Is diabetes mellitus an independent risk factor for colon cancer and rectal cancer? Am J Gastroenterol. 2011;106:1911-21.

40. Ma J, Pollak MN, Giovannucci E, Chan JM, Tao Y, Hennekens CH, et al. Prospective study of colorectal cancer risk in men and plasma levels of insulin-like growth factor (IGF)-I and IGF-binding protein-3. J Natl Cancer Inst. 1999;91:620-5.

41. Chao A, Thun MJ, Connell CJ, McCullough ML, Jacobs EJ, Flanders WD, et al. Meat consumption and risk of colorectal cancer. JAMA. 2005;293:172-82.

42. MacLennan R, Macrae F, Bain C, Battistutta D, Chapuis P, Gratten H, et al. Randomized trial of intake of fat, fiber, and beta carotene to prevent colorectal adenomas. J Natl Cancer Inst. 1995;87:1760-6.

43. Botteri E, Iodice S, Bagnardi V, Raimondi S, Lowenfels AB, Maisonneuve P. Smoking and colorectal cancer: a meta-analysis. JAMA. 2008;300:2765-78.

44. Pande M, Lynch PM, Hopper JL, Jenkins MA, Gallinger S, Haile RW, et al. Smoking and colorectal cancer in Lynch syndrome: results from the colon cancer family registry and the University of Texas M.D. Anderson Cancer Center. Clin Cancer Res. 2010;16:1331-9.

45. LoConte NK, Brewster AM, Kaur JS, Merrill JK, Alberg AJ. Alcohol and cancer: a statement of the American Society of Clinical Oncology. J Clin Oncol. 2018;36:83-93.

46. Fedirko V, Tramacere I, Bagnardi V, Rota M, Scotti L, Islami F, et al. Alcohol drinking and colorectal cancer risk: an overall and dose-response meta-analysis of published studies. Ann Oncol. 2011;22:1958-72.

47. Gillessen S, Templeton A, Marra G, Kuo YF, Valtorta E, Shahinian VB. Risk of colorectal cancer in men on long-term androgen deprivation therapy for prostate cancer. J Natl Cancer Inst. 2010;102:1760-70.

48. Lin JH, Giovannucci E. Sex hormones and colorectal cancer: what have we learned so far? J Natl Cancer Inst. 2010;102:1746-7.

49. Giovannucci E, Colditz GA, Stampfer MJ. A meta-analysis of cholecystectomy and risk of colorectal cancer. Gastroenterology. 1993;105:130-41.

50. van der Linden W, Katzenstein B, Nakayama F. The possible carcinogenic effect of cholecystectomy. No postoperative increase in the proportion of secondary bile acids. Cancer. 1983;52:1265-8.

51. Issa IA, Noureddine M. Colorectal cancer screening: an updated review of the available options. World J Gastroenterol. 2017;23:5086-96.

52. Boyle T, Keegel T, Bull F, Heyworth J, Fritschi L. Physical activity and risks of proximal and distal colon cancers: a systematic review and meta-analysis. J Natl Cancer Inst. 2012;104:1548-61.

53. Terry P, Giovannucci E, Michels KB, Bergkvist L, Hansen H, Holmberg L, et al. Fruit, vegetables, dietary fiber, and risk of colorectal cancer. J Natl Cancer Inst. 2001;93:525-33. 
54. Orlich MJ, Singh PN, Sabaté J, Fan J, Sveen L, Bennett H, et al. Vegetarian dietary patterns and the risk of colorectal cancers. JAMA Intern Med. 2015;175:767-76.

55. Bingham SA, Day NE, Luben R, Ferrari P, Slimani N, Norat T, et al; European Prospective Investigation into Cancer and Nutrition. Dietary fibre in food and protection against colorectal cancer in the European Prospective Investigation into Cancer and Nutrition (EPIC): an observational study. Lancet. 2003;361:1496-501.

56. Choi SW, Mason JB. Folate and carcinogenesis: an integrated scheme. J Nutr. 2000;130:129-32.

57. Cole BF, Baron JA, Sandler RS, Haile RW, Ahnen DJ, Bresalier RS, et al; Polyp Prevention Study Group. Folic acid for the prevention of colorectal adenomas: a randomized clinical trial. JAMA. 2007;297:2351-9.

58. Larsson SC, Orsini N, Wolk A. Vitamin B6 and risk of colorectal cancer: a meta-analysis of prospective studies. JAMA. 2010;303:1077-83.

59. Holt PR, Atillasoy EO, Gilman J, Guss J, Moss SF, Newmark H, et al. Modulation of abnormal colonic epithelial cell proliferation and differentiation by low-fat dairy foods: a randomized controlled trial. JAMA. 1998;280:1074-9.

60. Baron JA, Beach M, Mandel JS, van Stolk RU, Haile RW, Sandler RS, et al. Calcium supplements for the prevention of colorectal adenomas. Calcium Polyp Prevention Study Group. N Engl J Med. 1999;340:101-7.

61. Kim HS, Newcomb PA, Ulrich CM, Keener CL, Bigler J, Farin FM, et al. Vitamin D receptor polymorphism and the risk of colorectal adenomas: evidence of interaction with dietary vitamin $\mathrm{D}$ and calcium. Cancer Epidemiol Biomarkers Prev. 2001;10:869-74.

62. Grau MV, Baron JA, Sandler RS, Haile RW, Beach ML, Church TR, et al. Vitamin D, calcium supplementation, and colorectal adenomas: results of a randomized trial. J Natl Cancer Inst. 2003;95:1765-71.

63. Byers SW, Rowlands T, Beildeck M, Bong YS. Mechanism of action of vitamin D and the vitamin D receptor in colorectal cancer prevention and treatment. Rev Endocr Metab Disord. 2012;13:31-8.

64. Larsson SC, Bergkvist L, Wolk A. Magnesium intake in relation to risk of colorectal cancer in women. JAMA. 2005;293:86-9.

65. Rothwell PM, Wilson M, Elwin CE, Norrving B, Algra A, Warlow CP, et al. Long-term effect of aspirin on colorectal cancer incidence and mortality: 20-year follow-up of five randomized trials. Lancet. 2010;376:1741-50.

66. Meyskens FL Jr, McLaren CE, Pelot D, Fujikawa-Brooks S, Carpenter PM, Hawk E, et al. Difluoromethylornithine plus sulindac for the prevention of sporadic colorectal adenomas: a randomized placebo-controlled, double-blind trial. Cancer Prev Res (Phila). 2008;1:32-8.

67. Poynter JN, Gruber SB, Higgins PD, Almog R, Bonner JD, Rennert HS, et al. Statins and the risk of colorectal cancer. N Engl J Med. 2005;352:2184-92.

68. Kedika R, Patel M, Pena Sahdala HN, Mahgoub A, Cipher D, Siddiqui AA. Long-term use of angiotensin converting enzyme inhibitors is associated with decreased incidence of advanced adenomatous colon polyps. J Clin Gastroenterol. 2011;45:e12-6.

69. Boudreau DM, Koehler E, Rulyak SJ, Haneuse S, Harrison R, Mandelson MT. Cardiovascular medication use and risk for colorectal cancer. Cancer Epidemiol Biomarkers Prev. 2008;17:3076-80.

70. Park CH, Kim NH, Park JH, Park DI, Sohn CI, Jung YS. Individualized colorectal cancer screening based on the clinical risk factors: beyond family history of colorectal cancer. Gastrointest Endosc. 2018;88:128-35.

71. Obrand DI, Gordon PH. Continued change in the distribution of colorectal carcinoma. Br J Surg. 1998;85:246-8.

72. Plesko I, Boyle GS, Ondrusova M, Tomasek L, Kubik A. Dominant position of colorectal cancer in Slovakia: the old-new problem for cancer control. Neoplasma. 2008;55:10-5. 
73. Asteria CR, Pucciarelli S, Gerard L, Mantovani N, Pagani M, Boccia L, et al. The impact of colorectal screening program on the detection of right-sided colorectal cancer. A 5-year cohort study in the Mantua District. Int J Colorectal Dis. 2015;30:1627-37.

74. Asteria CR, Lucchini G, Guarda L, Ricci P, Pagani M, Boccia L. The detection of interval colorectal cancers following screening by fecal immunochemical test may predict worse outcomes and prompt ethical concerns: a 6-year population-based cohort study in a full district. Eur J Cancer Prev. 2019;28:17-26.

75. Ward ZJ, Bleich SN, Cradock AL, Barrett JL, Giles CM, Flax C, et al. Projected U.S. state-level prevalence of adult obesity and severe obesity. N Engl J Med. 2019;381:2440-50.

76. Dare S, Mackay DF, Pell JP. Relationship between smoking and obesity: a cross-sectional study of 499,504 middle-aged adults in the UK general population. PLoS One. 2015;10:e0123579.

77. Yap R, Wilkins S, Staples M, Oliva K, McMurrick PJ. The effect of diabetes on the perioperative outcomes of colorectal cancer surgery patients. PLoS One. 2016;11:e0167271.

78. Benoist S, Panis Y, Alves A, Valleur P. Impact of obesity on surgical outcomes after colorectal resection. Am J Surg. 2000;179:275-81. 